\title{
Fabrication of Sintered Diamond/Metal Composites and Evaluation of Grinding Performance for Sapphire
}

\author{
Makoto Inoue $^{1,2}$, Kenta Yasuda ${ }^{1}$, Tadashi Ito ${ }^{1}$, Tetsu Sasahara ${ }^{1}$, Masaru Yokota $^{1}$, Atsushi Nakahira ${ }^{2,3}$ \\ ${ }^{1}$ Nakamura Choto Co. Ltd., Sakai, Japan; ${ }^{2}$ Department of Material Science and Engineering, Osaka Prefecture University, Sakai, \\ Japan; ${ }^{3}$ Kansai-Center IMR, Tohoku University, Sakai, Japan. \\ Email: nakahira@mtr.osakafu-u.ac.jp
}

Received May $3^{\text {rd }}, 2012$; revised June $5^{\text {th }}, 2012$; accepted July $10^{\text {th }}, 2012$

\begin{abstract}
The fabrication of sintered diamond/metal composites bodies composed of diamond filler with the average particle size of $15 \mu \mathrm{m}$ to $30 \mu \mathrm{m}$ and metal binder (Ag-Cu-Ti system brazing) was attempted by powder metallurgical sintering process at $700^{\circ} \mathrm{C}$ to $1000^{\circ} \mathrm{C}$ in vacuum atmosphere. As a result, dense bulks of sintered diamond/metal composites were obtained by this powder metallurgical sintering process. The increase of sintering temperatures from $750^{\circ} \mathrm{C}$ to $950^{\circ} \mathrm{C}$ and of pressure enhanced the density of sintered diamond/metal composites during the hot-pressing in vacuum. All bulks prepared at the temperatures of $750^{\circ} \mathrm{C}$ to $950^{\circ} \mathrm{C}$ were composed of diamond phase and Ag-Cu-Ti system brazing without any other phase for sintered bulks for diamond/metal composites. Furthermore, some properties were evaluated for sintered diamond/metal composites.
\end{abstract}

Keywords: Diamond; Composite; Brazing; Ag; Microstructure; Grinding

\section{Introduction}

Needs for diamond tools like a diamond wheel, diamond blade and diamond tip for cutting and polishing ceramics, $\mathrm{Si}$ and sapphire ingots are still expanded in many application fields [1]. In general, diamond tools are classified into metal bonded type and resin bonded type. Although resin bonded diamond tools are composed of resin matrix and diamond fillers with desired particle size distributions, the cutting and grinding performances is rapidly degradated in spite of good cutting and grinding abilities. On the contrary, metal bonded diamond tools are generally fabricated by electric deposition of metal with various diamond fillers. These metal bonded diamond tools have good longterm performance, although their cutting and polishing abilities are relatively inferior to resin bonded diamond tools. Another metal bonded diamonds like a polycrystalline diamond (PCD) are also fabricated by the ultra high pressure (approximately 50,000 atm) equipment at high temperature (typical $1600^{\circ} \mathrm{C}$ ) for the diamond filler and Co binder [2]. In addition, the development of diamond-like carbon (DLC) films are reported with some methods such as plasma CVD and plasma based ion implantation by a lot of researchers [3]. Furthermore, the fabrications of some diamond-based composited containing another metal (for example, $\mathrm{Cu}$ and $\mathrm{W}$ ) and ceramics (for example, $\mathrm{SiC}$ and $\mathrm{Al}_{2} \mathrm{O}_{3}$ ) were attempted [4-7]. These PCD and DLC diamonds fabricated by various methods are extremely dense and expensive instead of good grinding and cutting performances, although they are generally machined and cut with electrical discharge machining [2].

On the other hand, silver brazing, typically $\mathrm{Ag}-\mathrm{Cu}-\mathrm{Zn}$, and other metal brazing systems are useful for the achievement of easily strong bonding of the different materials. Here we focus on the development of high performance diamond tools and bulks composed of diamond fillers and brazing as a metal binders, e.g. Ag-Cu-Ti system brazing through the powder metallurgical process. Using this powder metallurgical process, various microcomposites and nanocomposites, ceramics based composites and metal/ceramics hybrid composites, were developed and reported [8-10]. In special, this process will lead to the fabrication of dense diamond bulks with good machining ability and reasonable cost. Authors also reported the results of developments of Ag-Cu-Ti system brazing for diamond-coated SUS saw for cutting saw equipments. In this study, the fabrication of sintered diamond/ metal composites bodies composed of diamond filler and metal binder (Ag-Cu-Ti system brazing) was attempted by powder metallurgical sintering process in vacuum atmosphere. Furthermore, some properties were evaluated for these sintered diamond/metal composites.

\section{Experimental Procedures}

Commercial diamond filler with the average particle size 
of $15 \mu \mathrm{m}$ to $30 \mu \mathrm{m}$ from Tomei Diamond Co. Ltd. was used. As a metal binders, commercial powders for $\mathrm{Ag}-\mathrm{Cu}-\mathrm{Ti}$ system brazing (V1008-T) were used from Naisu Co. Ltd. Commercial diamond fillers were at first crushed with an alumina mortar, sufficiently washed with ethanol and dried at room temperature. The diamond fillers and metal binders (diamond content/Ag-Cu-Ti system brazing $=32$ $\mathrm{wt} \% / 68 \mathrm{wt} \%$ ) were mixed in ethanol by mortar and then dryly mixed by the ball milling method using $\mathrm{ZrO}_{2}$ ball media. Furthermore, PVA polymer ( $20 \%$ of mixtures) was added to these mixtures as a binder and mixed with mortar. After fully mixing, these mixtures were crushed with a mortar. Obtained powders were inserted in carbon dies and then heat-treated at $400^{\circ} \mathrm{C}$ for $60 \mathrm{~min}$. Then samples were sintered with hot-pressing equipments at $750^{\circ} \mathrm{C}$ to $950^{\circ} \mathrm{C}$ for 10 to $30 \mathrm{~min}$ (heating rate $10^{\circ} \mathrm{C}$ to $20^{\circ} \mathrm{C} / \mathrm{min}$ ) in vacuum atmosphere $\left(5 \times 10^{-3}\right.$ torr) with the applied pressure of $0.4 \mathrm{MPa}$ to $0.93 \mathrm{MPa}$ during the hot-pressing furnace in vacuum and subsequently slowly cooled in the hot-pressing furnace.

Sintered diamond/metal composites $(20 \mathrm{~mm}$ in diameter and $5 \mathrm{~mm}$ in thickness) were ground with diamond wheel and cut with diamond saw. The density of sintered diamond/metal composites was measured. The components of sintered diamond/metal composites were evaluated by XRD (Rint 2100, Rigaku Denki Co. Ltd.). The microstructure of sintered diamond/metal composites was observed by SEM (S4000, JEOL) and laser microscopy. The local compositions were measured by EDX analysis. Bulks of sintered diamond/metal composites were bonded with epoxy resin on the meal support for grinding test for sapphire.

\section{Results and Discussion}

Figure 1 shows the results of XRD of sintered diamond/ metal composites. All bulks sintered at the temperatures of $750^{\circ} \mathrm{C}$ to $950^{\circ} \mathrm{C}$ were composed of diamond phase and $\mathrm{Ag}-\mathrm{Cu}-\mathrm{Ti}$ system brazing without any other phase for sintered diamond/metal composites, as shown in figure. Thus, the increase of sintering temperatures from $750^{\circ} \mathrm{C}$ to $950^{\circ} \mathrm{C}$ had no reaction between diamond and $\mathrm{Ag}-\mathrm{Cu}-\mathrm{Ti}$ system brazing for the components of sintered diamond/metal composites during the hot-pressing in vacuum. Figure 2 indicates the variation of XRD patterns with the increase of pressure during the hot-pressing in vacuum for diamond/ metal composites sintered at $850^{\circ} \mathrm{C}$. The components of sintered diamond/metal composites were also composed of diamond and $\mathrm{Ag}-\mathrm{Cu}-\mathrm{Ti}$ system brazing phase. Therefore, the increase of pressure and sintering temperatures during the hot-pressing had no large influence on the components of composites and reaction between diamond and Ag-Cu-Ti system brazing for these sintered diamond/metal composites.

Figure 3(a) shows the results of density of sintered diamond/metal composites to investigate the influence of sin- tering temperatures (the pressure of $0.93 \mathrm{MPa}$ ). As shown in figure, the increase of sintering temperatures from $750^{\circ} \mathrm{C}$ to $950^{\circ} \mathrm{C}$ led to the slight increase of density of sintered diamond/metal composites during the hot-pressing in vacuum. In case of sintering at $850^{\circ} \mathrm{C}$, the maximum of density was achieved for bulks of diamond/metal composites. The increase of sintering temperatures a little enhanced the densification of these composites.

Furthermore, the variation of density with the applied pressure during the hot-pressing in vacuum was examined. Figure 3(b) shows the results of density of diamond/metal composites sintered at $850^{\circ} \mathrm{C}$. The increase of applied pressure during the hot-pressing in vacuum slightly indicated the same density of sintered diamond/metal composites during this hot-pressing system. Thus, these dense bulks of diamond/metal composites were obtained for the addition of metal binder of this Ag-Cu-Ti system brazing by this hot-pressing in vacuum. In special, the increase of sintering temperatures enhanced the densification for sintered diamond/metal composites during this hot-pressing system, although the pressure influence was small for the densification of these diamond/metal composites.

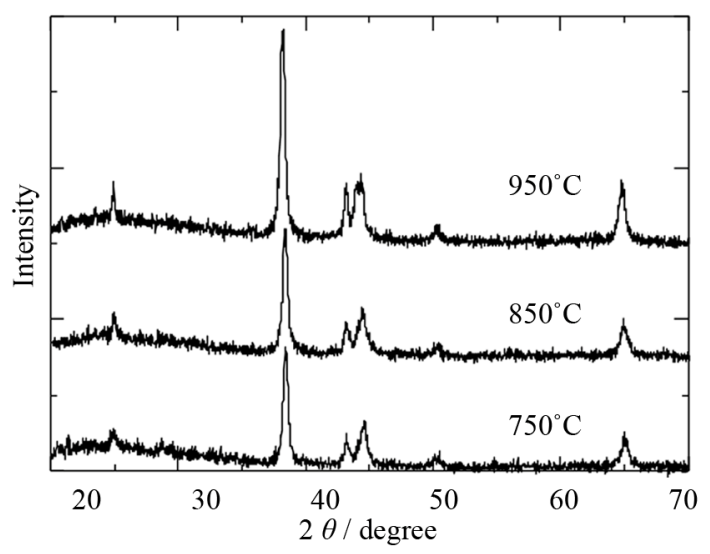

Figure 1. Results of XRD of sintered diamond/metal composites during the hot-pressing in vacuum.

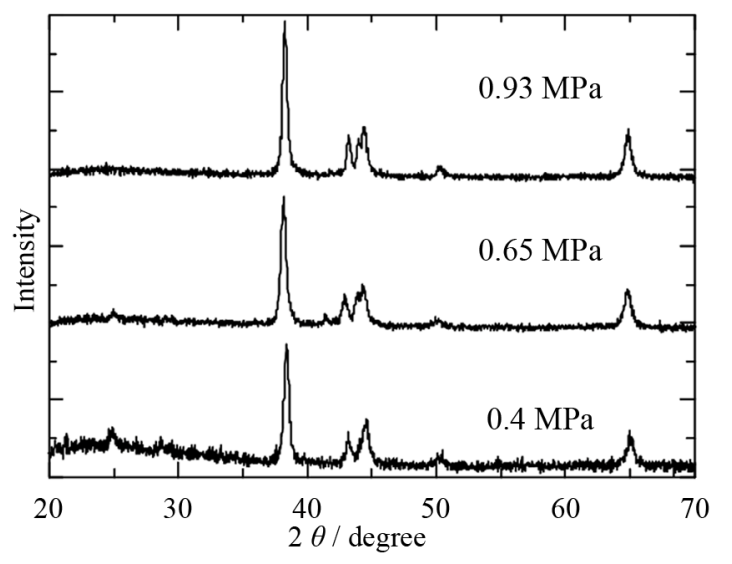

Figure 2. Variation of XRD patterns with the increase of pressure during the hot-pressing in vacuum. 


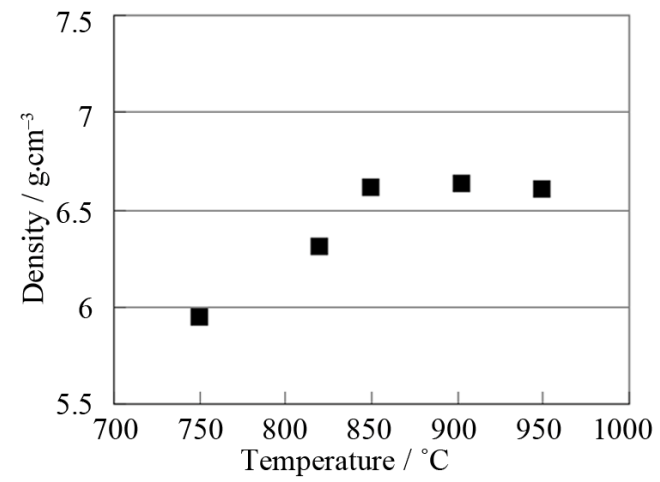

(a)

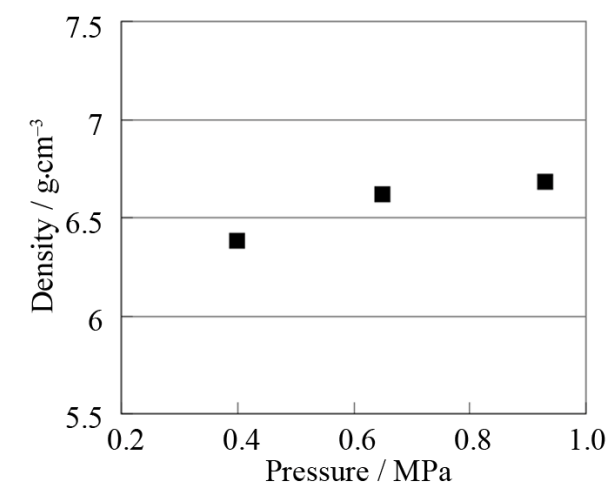

(b)

Figure 3. Results of density of sintered diamond/metal composites. (a) Influence of temperatures; (b) Influence of pressures.

Microstructures of sintered diamond/metal composites were observed with SEM and laser microscopy. Figure 4 shows images of SEM for bulks of sintered diamond/metal composites. Bulks of sintered diamond/metal composites were densified and diamond grains were filled with Ag$\mathrm{Cu}$-Ti system brazing phase as a metal binder. Diamond grains with average particle size of 15 to $30 \mu \mathrm{m}$ were homogeneously dispersed in $\mathrm{Ag}-\mathrm{Cu}-\mathrm{Ti}$ system brazing. From SEM observation, no large variation of grain size for diamond were confirmed after the hot-pressing sintering, suggesting that the reaction between the diamond and Ag-Cu-Ti system brazing as a metal binder was inhibited and no grain growth generated during this hotpressing sintering process. This result is coincident with the result of XRD.

Figure 5 shows the image from the laser microscopy for sintered diamond/metal composites bulks. In this figure, diamond grains were black parts and Ag-Cu-Ti system brazing were white and gray parts, respectively. From this image, it was found that the metal phases of $\mathrm{Ag}-\mathrm{Cu}-$ Ti system brazing were homogeneously located at grain boundary of diamond grains matrix, as shown in figure, after the hot-pressing sintering in vacuum. These observations indicated that $\mathrm{Ag}-\mathrm{Cu}$-Ti system brazing as a binder possessed the good wettability, leading to the densifica- tion of bulks for diamond/metal composites. From both results of observation using SEM and laser microscopy, it was obvious that the addition of metal binder of Ag$\mathrm{Cu}-\mathrm{Ti}$ system brazing into diamond grains inhibited the formation of the voids in the matrix of sintered bulks of diamond/metal composites and consequently the densification of these diamond/metal composites was achieved through the hot-pressing sintering process.

In addition, the EDX analysis of sintered diamond/metal composites was carried out for sintered diamond/metal composites bulks. Figure 6 shows the results of EDX analysis for sintered diamond/metal composites. White dots and parts were from the $\mathrm{Ag}, \mathrm{Cu}$ and $\mathrm{Ti}$ elements. As shown in figure, $\mathrm{Ag}$ and $\mathrm{Cu}$ elements were homogeneous dispersed in $\mathrm{Ag}-\mathrm{Cu}-\mathrm{Ti}$ system brazing parts of not in diamond grains, whereas $\mathrm{Ti}$ element was also detected in $\mathrm{Ag}-\mathrm{Cu}-\mathrm{Ti}$ system brazing parts for sintered diamond/metal composites. Thus, the grain boundaries of the diamond grains were filled with a metal binder of Ag-Cu-Ti system brazing and consequently the bulks of diamond/metal composites sintered by the hot-pressing in vacuum were densified with the liquid sintering of Ag-Cu-Ti system brazing.

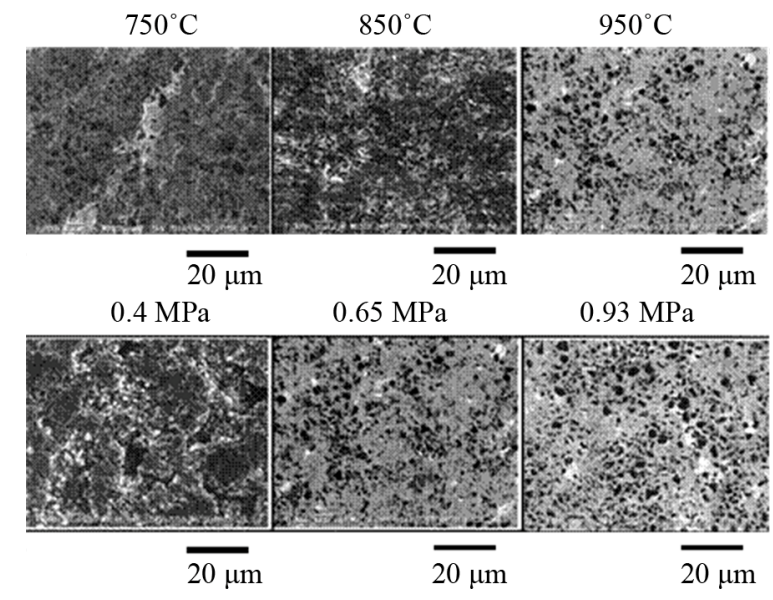

Figure 4. Images of SEM for bulks of sintered diamond/metal composites.

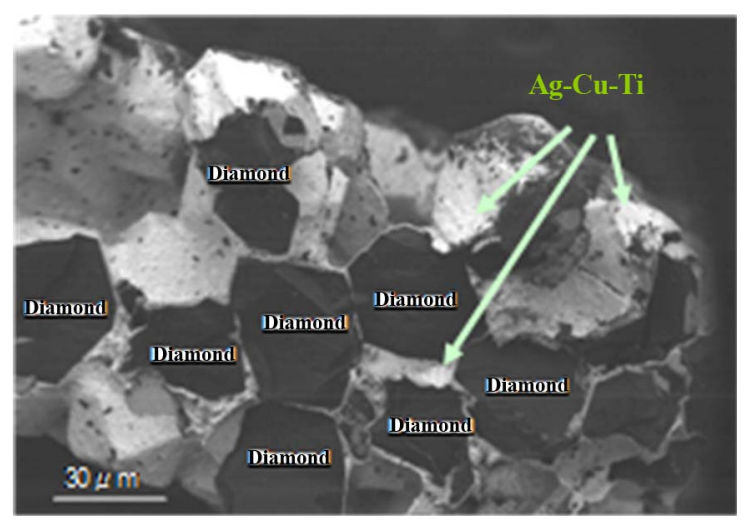

Figure 5. Image from the laser microscopy for sintered diamond/metal composites bulks. 


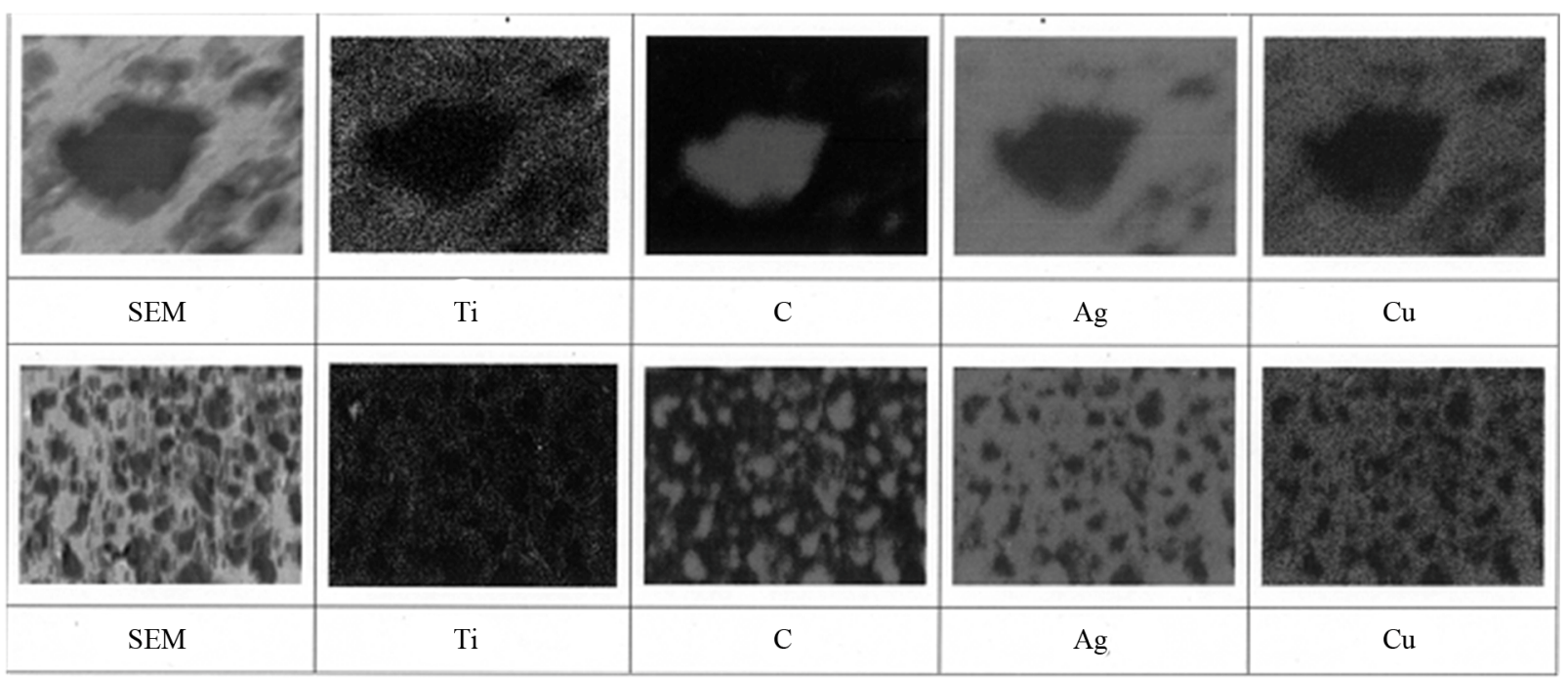

Figure 6. Results of EDX analysis for sintered diamond/metal composites.

Grinding performance was evaluated through the test of grinding the sapphire ingot. Figure 7 shows the SEM images of surface for the ground diamond/metal composites samples after the test of grinding the sapphire ingot. The surfaces without the large grinding flaws and drop-out of diamond for diamond/metal composites samples were obtained, as shown in figure, as well as the bulks of resin bonded diamond with average particle size of $15 \mu \mathrm{m}$ to $30 \mu \mathrm{m}$. After grinding the sapphire ingot, the significant degradation like debonding of diamond grains was not confirmed. Thus, before and after the test of grinding the sapphire ingot, no large difference of surface of sintered diamond/metal composites was observed. Consequently, these dense bulks of dia-mond/metal composites sintered in this study were obtained and possessed the good grinding ability for sapphire ingot.

\section{Conclusions}

The fabrication of sintered diamond/metal composites bodies composed of diamond filler and metal binder (Ag-CuTi system brazing) was attempted by powder metallurgical sintering process at $750^{\circ} \mathrm{C}$ to $950^{\circ} \mathrm{C}$ in vacuum atmosphere. The bulks of diamond/metal composites possessed the high density after hot-press sintering in vacuum. Microstructural observation indicated that diamond grains were homogeneously dispersed for bulks. From EDX analysis, $\mathrm{Ag}, \mathrm{Cu}$ and Ti elements were homogeneous dispersed in the grain boundaries of diamond grains and the reaction between the diamond and $\mathrm{Ag}-\mathrm{Cu}-\mathrm{Ti}$ system brazing as a metal binder was inhibited and no grain growth generated during this hot-pressing sintering process. From these observation, $\mathrm{Ag}$-Cu-Ti system brazing as a binder possessed the good wettability, leading to the densification of bulks for diamond/metal composites.

Thus, these dense bulks of sintered diamond/metal com-

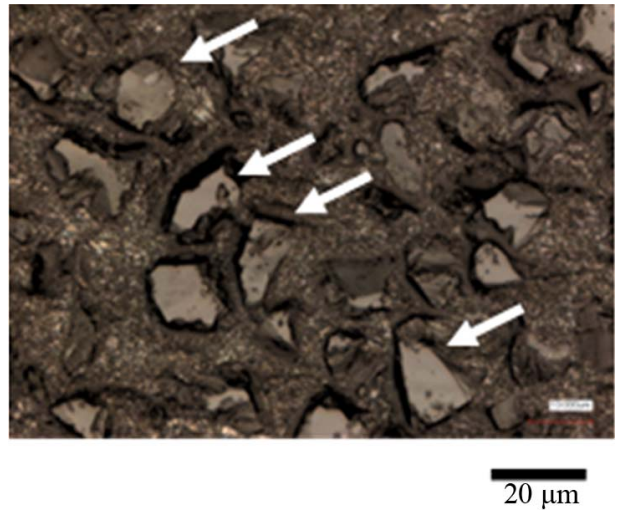

Figure 7. SEM images of surface for diamond/metal composites after the grinding the sapphire.

posites were obtained and possessed the good grinding ability for sapphire ingot. Grinding performance for sintered diamond/metal composites was due to the good bonding between diamond grains and $\mathrm{Ag}-\mathrm{Cu}-\mathrm{Ti}$ system brazing as a binder. Consequently, the dense bulks of sintered diamond/metal composites with the good grinding ability for sapphire ingot were successfully fabricated by this processing.

\section{REFERENCES}

[1] N. Funayama and J. Matsuda, "Development of HighPerformance cBN and Diamond Grinding Wheels for High-Speed Grinding," New Diamond and Frontier Carbon, Vol. 15, No. 4, 2005, pp. 173-180.

[2] S. Sano, M. Iwai, T. Uematsu and K. Suzuki, "Application of Polycrystalline Diamond (PCD) to EDM," Japan Society of Electrical-Machining Engineers, Vol. 42, No. 100, 2008, pp. 65-72. doi:10.2526/jseme.42.65

[3] W. Ensinger, "Formation of Diamond-Like Carbon Films by Plasma-Based Ion Implantation and Their Characteri- 
zations," New Diamond and Frontier Carbon, Vol. 16, No. 1, 2006, pp. 1-31.

[4] W. Z. Shao, V. V. Ivanovb, L. Zhena, Y. S. Cuia and Y. Wanga, "A Study on Graphitization of Diamond in Copper/Diamond Composite Materials," Materials Letters, Vol. 58, No. 1-2, 2004, pp. 146-149.

doi:10.1016/S0167-577X(03)00433-6

[5] Y. Chen, X. Jia, G. Zhao and X. Wang, "Facile Preparation of Cubic Calcium Carbonate Nanoparticles with Hydrophobic Properties via a Carbonation Route," Powder Technology, Vol. 200, No. 3, 2012, pp. 144-148. doi:10.1016/j.powtec.2010.02.017

[6] K. Mizuuchi, K. Inoue, Y. Agari, S. Yamada, M. Sugioka, M. Itami, M. Kawahara and Y. Makino, "Consolidation and Thermal Conductivity of Diamond Particle Dispersed Copper Matrix Composites Produced by Spark Plasma Sintering (SPS)," Journal of the Japan Institute of Metals, Vol. 71, No. 11, 2007, pp. 1066-1069.

doi:10.2320/jinstmet.71.1066
[7] M. Petrovic, A. Ivankovic and N. Murphy, "The Mechanical Properties of Polycrystalline Diamond as a Function of Strain Rate and Temperature," Journal of the European Ceramic Society, Vol. 32, No. 12, 2012, pp. 30213027. doi:10.1016/j.jeurceramsoc.2012.03.026

[8] A. Nakahira and K. Niihara, "Sintering Behaviors and Consolidation Process for $\mathrm{Al}_{2} \mathrm{O}_{3} / \mathrm{SiC}$ Nanocomposites," Journal of the Ceramic Society of Japan, Vol. 100, No. 1160, 1992, pp. 448-453. doi:10.2109/jcersj.100.448

[9] T. Ohji, A. Nakahira, T. Hirano and K. Niihara, "Tensile Creep Behavior of Aalumina/Silicon Carbide Nanocomposites," Journal of the American Ceramic Society, Vol. 77, No. 12, 1994, pp. 3259-3262. doi:10.1111/j.1151-2916.1994.tb04580.x

[10] A. Nakahira, H. Tamasa and K. Niihara, "Microstructure and Mechanical Properties for TiAl-Based Nanocomposites," Japan Society of Powder and Powder Metallurgy, Vol. 41, No. 6, 1994, pp. 514-518. 